\title{
UJI TEKAN POLYETHYLENE FIBER DENGAN FERULLE PADA INSISIVUS PERTAMA MAKSILA
}

\author{
Anita*, Erna Kurnikasari**, Aprilia Adenan** \\ *Program Pendidikan Dokter Gigi Spesialis Prostodonsia, \\ Fakultas Kedokteran Gigi Universitas Padjadjaran, Bandung \\ **Departemen Prostodonsia, Fakultas Kedokteran Gigi Universitas Padjadjaran, Bandung \\ Korespondensi: Anita, stefanianita@ymail.com
}

\begin{abstract}
ABSTRAK
Latar belakang: pasak intraradikuler terbukti dapat memberikan dukungan pada restorasi gigi yang telah dirawat endodontik. Fiber reinforced composite memiliki modulus elastisitas mendekati dentin, dimana hal ini baik untuk menyalurkan tekanan kunyah ke akar. Polyethylene fiber merupakan jenis pasak yang banyak berkembang belakangan ini karena memiliki kelebihan mudah dibentuk serta memberikan estetik yang baik. Tujuan: penelitian ini bertujuan untuk mengetahui kekuatan tekan polyethelene fiber sebagai bahan pasak inti pada gigi insisivus pertama maksila. Metode: sampel sebanyak 7 gigi insisivus pertama maksila yang telah dirawat endodontik, dibuatkan pasak dan inti. Hasil: dilakukan uji tekan pada permukaan palatal inti komposit dengan sudut 135 derajat terhadap sumbu panjang gigi, diperoleh nilai uji tekan paling tinggi sebesar 661,62 N dan paling rendah sebesar 120,27 N. Hasil uji tekan memiliki nilai rata-rata uji tekan sebesar 438,57 N, dengan standar deviasi 177,82. Daya kunyah rata-rata pada insisivus pertama pada pria yaitu 147,17 N, dan pada wanita yaitu 93,88 N. Kesimpulan: polyethylene fiber dengan akhiran ferulle dapat digunakan sebagai bahan pasak yang mampu menahan daya kunyah pada gigi insisivus pertama maksila.
\end{abstract}

Kata kunci: uji tekan, polyethylene fiber, ferulle

\begin{abstract}
Background: intraradicular post has been proved to support endodontic tooth. Fiber reinforced composite have modulus elasticity closed to dentin, which is better to distribute masticatory forces to the tooth. Polyethylene fiber post has develop lately because the advantages easy to build and give better esthetic. Purpose: the aims of this research is to determine compressive strength of polyethylene fiber as material post core at central insisivus maxilla. Methods: seven central insisivus tooth was treated with endodontic treatment, built up with post core. Result: compressive load was applied from the palatal at angle of 135 degrees to the long axis of teeth, the highest compressive strength was 661,62 N and the lowest was 120,27 N. The average of compressive strength was 438,57 N, with a standard deviation 177,82. The average compressive load in cental insisivus 146,17 N in men, and 93,88 $\mathrm{N}$ in woman. Conclusion: polyethylene fiber with ferulle can be used as material of post core which can resist masticatory forces at central insisivus.
\end{abstract}

Keywords: compressive strength, polyethylene fiber, ferulle

\section{PENDAHULUAN}

$\mathrm{G}$ igi yang telah dirawat endodontik menjadi lebih rapuh karena kehilangan sebagian strukturnya, berkurangnya kelenturan gigi, perubahan ikatan kolagen, kelembaban, serta terjadi dehidrasi gigi. Pelebaran saluran akar dan preparasi kavitas dapat mempengaruhi kekuatan pada gigi, sehingga gigi menjadi rapuh sebagai akibat dari perawatan saluran akar. ${ }^{1,2}$ Jumlah struktur gigi yang tersisa merupakan indikator kesuksesan dari suatu perawatan endodontik. Jika terdapat lebih dari $2 \mathrm{~mm}$ struktur gigi yang tersisa di bagian koronal gigi, maka terdapat resistensi dari gigi yang direstorasi. ${ }^{3}$

Perpanjangan dari dinding aksial pada daerah servikal gigi yang dipreparasi memberikan kekuatan pada gigi yang akan direstorasi, hal ini disebut sebagai ferulle. Ferulle didefinisikan sebagai cincin yang mengelilingi permukaan gigi / bagian servikal yang mengellilingi inti. Hal ini berfungsi untuk mengikat struktur gigi yang tersisa sehingga dapat mencegah 
terjadinya fraktur pada akar. ${ }^{3}$ Penggunaan pasak dan inti telah lama digunakan sebagai bahan dasar untuk mendukung restorasi akhir gigi yang telah dirawat endodontik pada kasus kehilangan struktur yang luas. Jenis pasak yang digunakan antara lain custom dan prefabricated. $^{2}$

Fiber reinforced composite / FRC merupakan kombinasi dari fiber dan matriks resin, dimana karateristik dari FRC bergantung dari tipe fiber (Glass, Carbon, Polyethylene, Aramid), jumlah dari fiber, struktur / orientasi dari fiber, posisi fiber, adesi fiber dengan resin matriks, kualitas dari fiber impregnation dan penyerapan air pada matriks FRC. ${ }^{4,5}$ Polyehylene fiber merupakan jenis FRC yang banyak digunakan dalam kedokteran gigi, dimana jenis fiber ini dapat diaplikasikan langsung dan berbentuk custom jika digunakan sebagai bahan pasak. Ultra high molecular weight (UHMW) polyethyelene fiber yang dilapisi dengan bonding dentin sering digunakan untuk membangun pasak dan inti pada gigi yang telah dirawat endodontik. . $^{5,6,7,8}$

Anyaman pita fiber ini memiliki pola cross linked, dimana lock sttiched threads dapat meningkatkan kekuatan dan stabilitas fiber. Anyaman pita yang rapat ini bertujuan untuk menghindari terjadinya perubahan dari pita fiber pada saat manipulasi dan adaptasi sebelum terjadi polimerisasi. Pola anyaman ini dapat beradaptasi dengan permukaan gigi, bahkan dengan lengkung gigi sehingga dapat membentuk ikatan mekanis dengan resin komposit dan meminimalisasi terjadinya keretakan resin selama polimerisasi. ${ }^{5,7,9}$

Anyaman pita ini memiliki modulus elastisitas mendekati dentin dan diklaim dapat menciptakan monoblock dentin post core system sehingga dapat menyalurkan distribusi tekanan ke akar. Jenis fiber ini tidak diperlukan pembesaran pada saluran akar, dimana pembesaran saluran akar dapat beresiko terjadi perforasi pada saluran akar. ${ }^{8}{ }^{10}$ Berbagai kelebihan dari jenis fiber ini antara lain translusen sehingga memberikan estetik yang lebih baik dibandingkan pasak logam, memiliki fleksibilitas yang tinggi, mudah dalam aplikasi dan dapat digunakan dalam 1 kali kunjungan. ${ }^{6,8,10}$

Kegunaan UHMW polyethylene fiber dalam berbagai bidang kedokteran gigi antara lain dalam bidang prostodonti sebagai direct fixed bridge pada kehilangan satu gigi dan sebagai bahan pasak direct pada gigi yang telah dirawat endodontik, dalam bidang konservasi sebagai struktur penguat pada kavitas yang luas, dalam bidang pedodonti sebagai bahan pasak dalam saluran akar, dalam bidang ortodonti sebagai lingual retainer, dalam bidang periodonti untuk fiksasi pada gigi goyang. ${ }^{6,8,9}$

\section{METODE PENELITIAN}

Penelitian merupakan penelitian eksperimental murni, perlakuan dilakukan pada gigi insisivus pertama maksila yang sudah diesktraksi. Penelitian ini dilakukan pada bulan Agustus 2016 sampai dengan September 2016 di Laboratorium Prostodonsia dan ITMKG Fakultas Kedokteran Gigi Universitas Padjajaran Bandung.

Sampel dipilih dari sejumlah gigi insisivus pertama maksila yang dikumpulkan dari berbagai klinik dan puskesmas di Kota Bandung. Sampel diambil dengan kriteria secara visual memiliki ukuran yang hampir sama, tidak terdapat karies, tidak terdapat restorasi, belum pernah dilakukan perawatan saluran akar dan tidak terdapat fraktur/retakan. Pemeriksaan terhadap fraktur dilakukan dengan menggunakan alat bantu kaca pembesar. Semua sampel akan dibuatkan preparasi berbentuk ferulle. Pembuatan pasak dari polyethylene fiber dan inti dari bahan resin komposit sesuai dengan bentuk inti gigi insisivus pertama maksila.

Variabel pengaruh dalam penelitian ini yaitu pasak dari polyethylene fiber. Variabel terpengaruh dalam penelitian ini yaitu kekuatan tekan pasak polyethylene fiber pada gigi dengan bentuk preparasi ferulle hingga terjadi fraktur. Variabel terkendali dalam penelitian ini yaitu kondisi gigi secara visual, ukuran gigi (panjang gigi dari insisal ke apikal), panjang dan bentuk preparasi saluran akar, panjang kerja pasak, bentuk inti komposit (lebar, panjang, tebal), bahan inti komposit, bahan semen, dan teknik penyemenan, pemendaman dalam tabung berisi self curing akrilik, prosedur pengujian menggunakan alat dan kecepatan uji. Variabel tidak terkendali dalam penelitian ini yaitu struktur dentin insisivus pertama rahang atas, umur gigi setelah pencabutan, alasan pencabutan gigi.

Prosedur yang dilakukan pada penelitian ini:

1) Preparasi saluran akar

Seluruh mahkota gigi dikurangi dalam arah horizontal sebanyak $3 \mathrm{~mm}$ dari tepi insisal hingga terlihat kamar pulpa dengan diamond bur tipe flat end wheel. Saluran akar dipreparasi menggunakan Protaper hand use (Dentsply) hingga ukuran F3. Irigasi menggunakan sodium hipoklorit 2,5\% selama preparasi saluran akar.

Jika selama preparasi saluran akar ditemukan gigi yang terlalu besar sehingga longgar setelah dipreparasi dengan file Protaper F3, maka gigi tersebut tidak disertakan dalam populasi sampel. Pengisian saluran akar menggunakan pasta $\mathrm{AH}$ Plus (Dentsply) sebagai sealer kemudian dilakukan pengisian saluran akar menggunakan guttaperca Protaper ukuran F3.

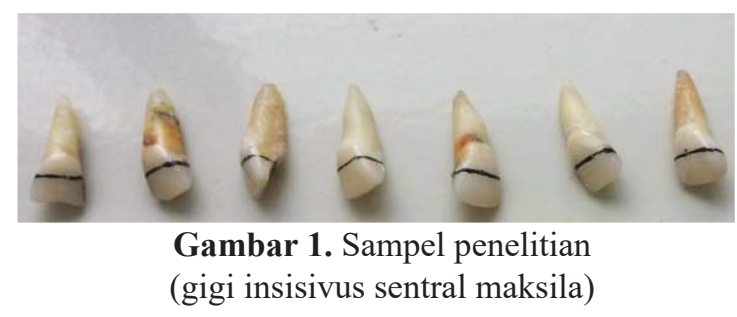




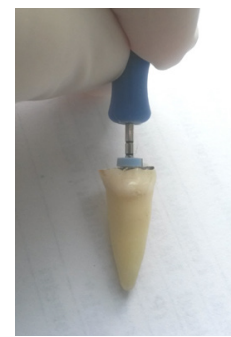

(A)

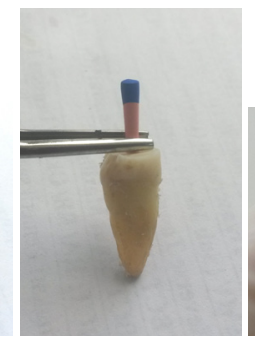

(B)

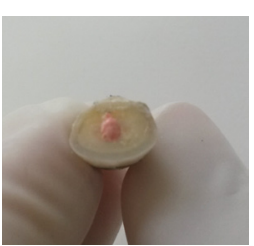

(C)
Gambar 2. Sampel penelitian (A) Preparasi saluran akar menggunakan Protaper hingga ukuran F3, (B) Pengisian saluran akar menggunakan Guttap, (C) Pemotongan guttap

2) Preparasi ferulle dan preparasi panjang kerja pasak Gigi insisivus pertama rahang atas sebanyak 7 buah dibuatkan pasak dengan bahan polyethylene fiber (Ribbond) sesuai dengan panjang kerja pasak. Kemudian pembuangan sisa mahkota bagian insisal hingga ketinggian $2 \mathrm{~mm}$ diatas cementoenamel junctional. Bentuk preparasi ferulle pada seluruh sampel. Preparasi saluran akar pada hingga meninggalkan paling sedikit $4 \mathrm{~mm}$ guttap di apikal.

3) Penyemenan pasak

Penyemenan pasak dilakukan setelah mengukur panjang kerja saluran akar. Panjang polyethylene fiber yang digunakan yaitu $2 \mathrm{x}$ panjang kerja. Lebar pita fiber yang digunakan $2 \mathrm{~mm}$. Saluran akar diirigasi dengan $\mathrm{NaOCl}$, keringkan dengan paper point, Primer A dan B diaplikasikan ke salam saluran akar (15 detik) lalu keringkan dengan paper point. Bahan adhesive diaplikasikan ke permukaan pasak (60 detik), keringkan dengan udara. Semen resin ditempatkan ke dalam dinding saluran akar dengan lentulo, polyethylene fiber ditekan masuk ke dalam saluran akar menggunakan endodontic plugger, sisa polyethylene fiber ditekuk dibagian koronal, sisa semen dibersihkan, lalu disinar menggunakan alat light curing selama 40 detik.
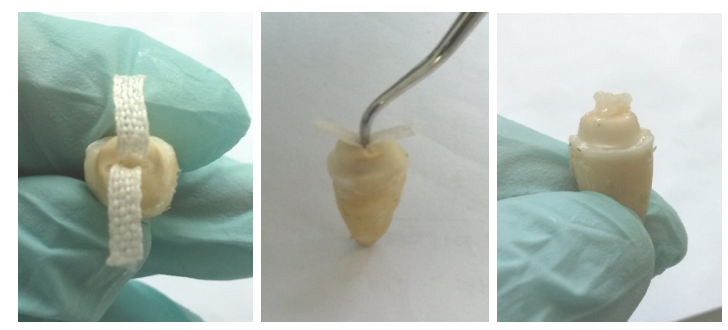

Gambar 3. Penyemenan pasak polyethylene fiber

4) Pemendaman akar gigi pada akrilik self curing

Tiap sampel dipendam dalam tabung berisi self curing dengan ukuran tinggi $21 \mathrm{~mm}$ dan diameter $15 \mathrm{~mm}$. Pada kedua kelompok sampel, kepala fiber difiksasi dengan bantu fiksasi dengan tujuan agar stabil pada saat ditanam ke dalam tabung berisi self curing akrilik. Sampel diposisikan ditengah tabung hingga batas cemento-enamel junction, sampel difiksasi hingga self curing mengeras.

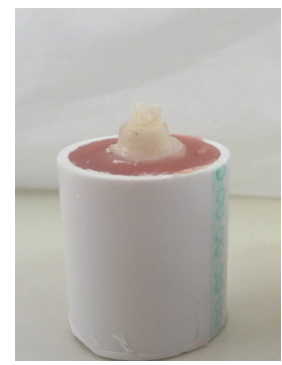

Gambar 4. Pemendaman sampel ke dalam tabung berisi self curing akrilik

5) Pembuatan inti dari bahan core build up

Bagian inti dibuat dari bahan resin komposit core build up (Build-It FR, Pentron). Bagian dentin di koronal yang tersisa di etsa menggunakan phosphoric acid $37 \%$ selama 15 detik, dibilas dan dikeringkan berdasarkan instruksi. Bonding (Bond1 Primer Adhesive, Pentron) diaplikasikan pada bagian dentin yang tersisa, disinar menggunakan light curing selama 20 detik. Dibuat cetakan inti komposit dengan elastomer konsistensi putty, sehingga tiap sampel memiliki bentuk inti yang sama (tinggi, lebar, dan tebal). Bahan core build up diisi ke dalam cetakan elastomer, lalu tiap kepala pasak direkatkan ke dalam cetakan elastomer yang sudah berisi bahan core build up. Lakukan penyinaran dengan light curing selama 40 detik. Ukuran dan ketebalan inti dari komposit diperiksa standarisasinya pada semua sampel dengan menggunakan jangka sorong. Sampel diposisikan ke dalam metal jig yang telah dibuat, lalu siap dilakukan uji tekan menggunakan alat Universal Testing Machine.
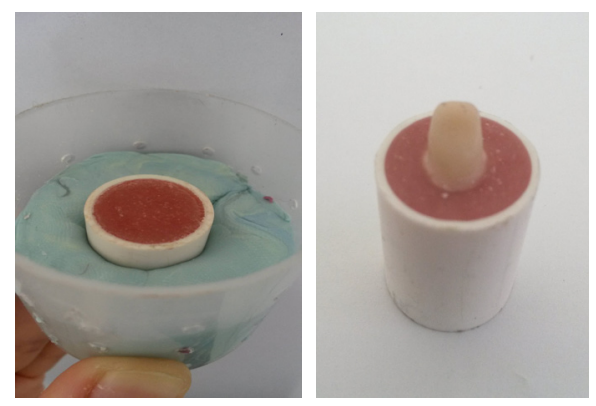

Gambar 5. Pembuatan inti komposit

6) Pengujian sampel

Pengujian ketahanan fraktur pasak dilakukan menggunakan Universal Testing Machine Instron. Gaya tekan diaplikasikan pada permukaan palatal 
inti komposit pada sudut $135^{\circ}$ terhadap sumbu panjang gigi. Alat uji diaktifkan dengan kecepatan $5,0 \mathrm{~mm} /$ menit hingga terjadi fraktur. Hasil uji tekan ini akan terlihat pada monitor dan dicatat dalam ukuran Newton. Besarnya gaya tekan hasil pengujian sampel menentukan ketahanan fraktur masing-masing pasak.
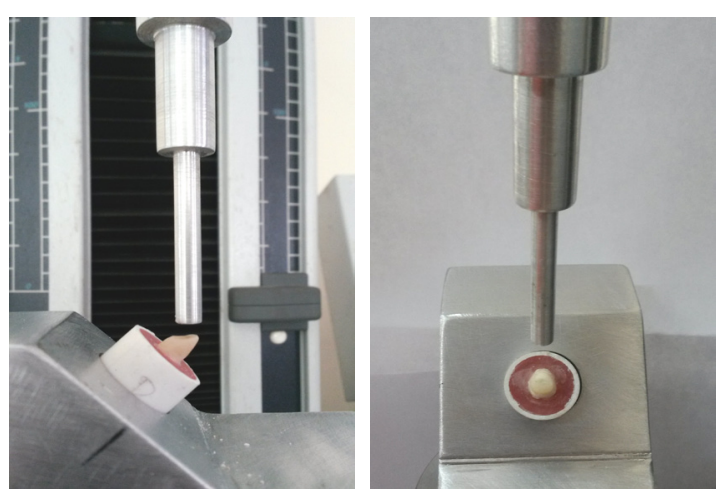

Gambar 6. Cara pengujian sampel

\section{HASIL PENELITIAN}

Berikut merupakan tabel hasil uji tekan pasak polyethylene fiber yang dilakukan terhadap 7 sample gigi.

Tabel 1. Nilai rata-rata kekuatan tekan pasak polyethylene fiber dalam satuan Newton $(\mathrm{N})$

\begin{tabular}{ccccc}
\hline Sampel & $\begin{array}{c}\text { Uji Tekan } \\
\text { Polyethylene fiber }\end{array}$ & $\mathbf{n}$ & Rerata & $\begin{array}{c}\text { Std. } \\
\text { Deviasi }\end{array}$ \\
\hline 1 & 553,99 & 7 & 438,57 & 177,82 \\
2 & 661,62 & & & \\
3 & 394,93 & & & \\
4 & 120,27 & & & \\
5 & 570,35 & & & \\
6 & 394,53 & & & \\
7 & 374,35 & & \\
\hline
\end{tabular}

Hasil uji tekan pada 7 sampel dengan nilai uji tekan paling tinggi $661,62 \mathrm{~N}$, sedangkan uji tekan paling kecil 120,27 N, dengan nilai rata-rata uji tekan $438,57 \mathrm{~N}$ dan standar deviasi 177,82 .

\section{PEMBAHASAN}

Pembuatan pasak dan inti merupakan tahapan penting dalam prostetik sebagai pendukung restorasi akhir gigi yang dirawat endodontik. ${ }^{11}$ Pemilihan pasak yang digunakan bergantung dari posisi gigi dalam lengkung rahang, jumlah strukstur gigi yang tersisa dan kebutuhan akan estetik. Tujuan dari pembuatan pasak yaitu memberikan retensi yang optimal pada pasak dan memberikan dukungan terhadap mahkota. Pasak merupakan bahan rigid yang dimasukkan ke dalam saluran akar setelah dilakukan perawatan endodontik. Beberapa penelitian menganjurkan rigidity dari pasak sebaiknya sama dengan akar. Dalam hal ini modulus elastisitas dari pasak sebaiknya mendekati elastisitas dari dentin, hal ini bertujuan agar dapat mentrasmisikan tekanan dari pasak ke struktur akar secara efisien. ${ }^{1}$

Sifat ideal bahan dari pasak yaitu memiliki sifat fisik seperti modulus elastisitas, compressive strength, flexural strength, dan ekspansi termal mendekati dentin. Dapat memberikan hasil estetik dan memiliki perlekatan yang baik dengan dentin. Jika terjadi perbedaan modulus elastisitas antara dentin dan bahan pasak, mungkin saja terjadi konsentrasi tekanan berlebih pada dentin yang berpotensi terjadinya fraktur akar. ${ }^{11}$ Perogetti dkk. merekomendasikan bahan pasak yang ideal yaitu yang memiliki modulus elastisitas mendekati dentin, karena beberapa bahan tidak secara signifikan dapat menyalurkan distribusi tekan terhadap dentin, hal ini dapat menyebabkan kegagalan pada restorasi. ${ }^{11}$

Modulus elastisitas pada dentin sekitar 18,6 Gpa, modulus elastisitas polyethylene fiber reinforced composite sekitar 23,6 Gpa. ${ }^{11}$ Pola distribusi pada gigi dengan pulpa vital tentu saja berbeda pada gigi yang telah dirawat endodontik. Perbedaan kekakuan dari pasak tidak dapat disamakan dengan struktur denitn, oleh karena itu bahan pasak disarankan memiliki sifat mekanis mendekati dentin. ${ }^{12}$

Penelitian ini merupakan penelitian in vitro, pengujian sampel dilakukan dengan memberikan tekanan pada permukaan palatal inti komposit dengan sudut $135^{\circ}$ terhadap sumbu panjang gigi. Sudut ini diilustrasikan sebagai tekanan yang jatuh pada gigi insisivus pertama rahang atas dalam keadaan intraoral. Berbagai penelitian dilakukan oleh Li dkk. ${ }^{11}$, Furtado dkk. ${ }^{13}$ juga menggunakan angulasi titik beban yang sama sehingga jatuh pada permukaan palatal gigi insisivus pertama rahang atas dengan sudut $135^{\circ}$ terhadap sumbu panjang gigi.

Terdapat beberapa penelitian yang menggunakan polyethylene fiber baik sebagai faktor penguat pada kavitas yang luas, maupun sebagai bahan pasak pada gigi anterior maupun posterior. Akman dkk. ${ }^{9}$ memastikan bahwa gigi anterior yang menggunakan polyethylene fiber dalam saluran akar menunjukkan ketahanan terhadap fraktur paling tinggi. ${ }^{9}$ Ayna dkk. ${ }^{9}$ dan Badakar dkk. ${ }^{10}$ memastikan penggunaan polyethylene fiber dalam saluran akar yang dikombinasikan dengan resin komposit efisien untuk merawat gigi anterior. ${ }^{9}$ Selain itu, Uzun dkk. ${ }^{14}$ melaporkan penggunaan polyethylene fiber secara signifikan dapat meningkatkan kekuatan dan modulus elastisitas. $^{14}$

Polyethylene fiber belakangan ini banyak digunakan sebagai bahan pasak pada gigi tetap karena 
bentuknya yang elastis, dan juga tidak diperlukan pembesaran dari saluran akar. jenis pita fiber ini dapat dibentuk menyesuaikan dengan penampang saluran akar, sehingga tidak diperlukan bur khusus dalam saluran akar, selain itu banyak juga digunakan pada saluran akar dengan diameter yang lebar (dengan kombinasi dengan prefabricated glass fiber). Diperlukan teknik khusus untuk menyementasikan pita fiber ini dalam sakuran akar, karena bentuknya yang elastis tentunya panjang pita fiber yang digunakan harus diperhatikan. Umumnya menggunakan 2 kali panjang kerja, dibentuk V, masukan ke dalam saluran akar, diisi semen resin, lalu kelebihan pita fiber ditekuk dibagian servikal untuk membentuk inti

Prosedur adhesive dan bonding harus diperhatikan dalam penggunaan pasak jenis ini. Kebanyakan faktor kegagalan dari pasak fiber reinforced composite yaitu dalam hal debonding. Oleh karena itu pemilihan semen yang tepat dan tahapan dalam sementasi harus diperhatikan. Kekurangan dari polyethtlene fiber ini yaitu sulitnya menentukan standar dimensinya. Kekuatan pita fiber ini dalam saluran akar ditentukan oleh jumlah pita fiber dan bahan komposit yang terdapat di dalam saluran akar. Semakin besar saluran akar, maka kekuatan pita fiber semakin baik karena jumlah pita fiber yang digunakan semakin banyak dan juga semen resin yang digunakan semakin banyak dibandingkan dengan saluran akar yang sempit. ${ }^{15}$

Penelitian ini menggunakan akhiran ferulle, tujuan pembuatan ferulle yaitu meningkatkan integritas struktural pada gigi yang telah kehilangan pulpa untuk menahan gaya fungsional, wedging effect pada pasak dan gaya lateral pada saat pemasangan pasak. Ferulle dapat meningkatkan resistensi pada pasak/inti/ mahkota sehingga dapat mencegah terjadinya rotasi, ferulle juga dapat mengurangi tegangan akibat tekanan yang terjadi pada dentin bagian labial serta dinding saluran akar. ${ }^{16}$

Ferrule merupakan perpanjangan dinding aksial, diilustrasikan sebagai pita logam atau cincin yang mengelilingi inti yang berfungsi untuk mengikat struktur gigi yang tersisa dan mencegah terjadinya fraktur akar selama fungsi pengunyahan. Ferulle seharusnya memiliki minimum tinggi 1-2 mm, pararel dengan dinding aksial, secara utuh mengelilingi gigi, dan tidak menyentuh bagian penyangga gigi. ${ }^{16}$

Libman dan Nicholls ${ }^{12}$ pada tahun 1995 melaporkan penggunaan ferulle meningkatkan resistensi terhadap frakur hal ini berhubungan dengan kerapatan semen didaerah servikal, jika terdapat perpanjangan mahkota didaerah cementoenamel junction dengan minimal ketinggian 1,5 mm. Penelitian menggunakan finite element juga menunjukkan jika tidak terdapat ferulle dibagian servikal, hal ini memberikan efek negatif yaitu meningkatkan tingkatan stress di daerah

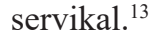

Penelitian ini memberikan nilai kekuatan tekan paling tinggi $661,62 \mathrm{~N}$, dan nilai paling tekan paling rendah rendah $120,27 \mathrm{~N}$. Variasi dari nilai uji tekan ini mungkin saja dipengaruhi dari titik beban yang jatuh pada permukaan palatal inti komposit tiap sampel. Titik beban berbentuk silindris, sehingga permukaan yang berkontak dengan permukaan palatal inti komposit dapat saja sedikit bergeser pada saat dilakukan uji tekan, dimana hal ini akan memberikan nilai uji tekan yang bervariasi.

Uji tekan pada penelitian ini mengunakan tabung berukuran tinggi $21 \mathrm{~mm}$ dan diameter $15 \mathrm{~mm}$. Seluruh tabung distandarisasi tinggi dan diameternya, tabung berfungsi sebagai pemegang sampel yang diposisikan ke dalam jig metal pada saat diuji tekan. Tentunya tinggi dan diameter tabung akan mempengaruhi hasil dari kekuatan tekan, tetapi akan mempengaruhi hasil secara keseluruhan.

Daya kunyah rata-rata (pada usia 19-29 tahun) pada gigi insisivus sentral pada laki-laki sekitar 146,17 $\mathrm{N}$, sedangkan pada wanita sekitar 93,88 N. ${ }^{17}$ Hasil kekuatan tekan rata-rata polyethylene fiber yang diteliti yaitu 438,57 N dimana angka ini melebihi daya kunyah pada manusia, sehingga disimpulkan penggunaan kedua jenis pasak ini dapat digunakan secara klinis.

Perludiingatbahwa dayakunyah bergantung dari morfologi cranio-facial, usia, jenis kelamin, kesehatan jaringan periodontal, kelainan temporomandibular, dan kesehatan gigi. Selain itu, keadaan klinis gigi sendiri juga perlu dipertimbangkan apakah jaringan yang tersisa di bagian koronal cukup banyak dan tebal atau tidak. ${ }^{18}$ Berbagai aspek mempengaruhi keberhasilan suatu gigi yang telah dirawat endodontik, oleh karena itu seleksi kasus serta rencana perawatan yang akan dilakukan perlu diperhatikan dengan seksama untuk mendapatkan perawatan yang maksimal.

Penelitian in vitro ini memiliki keterbatasan seperti penelitian-penelitian sebelumnya. Penelitian ini tidak dapat meniru kondisi klinis yang sebenarnya terjadi di dalam mulut sehingga hasil penelitian ini tidak dapat secara langsung diaplikasikan secara klinis. Hal ini disebabkan banyak kondisi klinis yang tidak dapat disimulasikan dalam penelitian ini, seperti contoh ligamen periodontal, kelembaban dalam mulut, simulasi saliva, tulang alveolar, dan gaya-gaya dalam sistem pengunyahan. Selain itu, kerapatan semen di dalam saluran akar juga tidak dapat kita ketahui secara pasti, terutama pada penggunaan polyethyelene fiber sebagai bahan pasak dalam saluran akar.

\section{KESIMPULAN DAN SARAN}

Dari penelitian ini dapat disimpulkan bahwa penggunaan polyethylene fiber sebagai bahan pasak dalam saluran akar yang normal / tidak melebar dengan kombinasi semen resin, dapat digunakan secara klinis untuk menahan daya kunyah pada gigi insisivus sentral maksila. 
Dari penelitian ini dapat kita ketahui bawah penggunaan polyethylene fiber yang mudah diaplikasikan, dengan 1 kali kunjungan, dan juga cukup kuat dapat dimaanfaatkan sehari-hari dalam praktek kedokteran gigi. Penelitian ini menggunakan 7 gigi insisivus yang telah dirawat endodontik dan dibuatkan pasak dan inti dengan akhiran ferulle, lalu dilakukan uji tekan pada permukaan palatal inti komposit dengan sudut 135 derajat terhadap sumbu panjang gigi, diperoleh nilai rata-rata uji tekan yaItu $438,57 \mathrm{~N}$.

\section{DAFTAR PUSTAKA}

1. Mortazavi V, Fathi M, Katiraei N, Shahnaseri S, Badrian $\mathrm{H}$, Khalighinejad. Fracture resistance of structurally compromised and normal endodontically treate $\mathrm{d}$ teeth restored with different post systems: in vitro study. Dental Res J. 2012 ;9(2): 185-9.

2. Bolay S, Ozturk E, Tuncel B, Ertan A. Fracture resistance treated teeth restores with or without post systems. JDS. $2012 ; 7: 149$.

3. Rosenstiel, Land, Fujimoto. 2006. Contemporary fixed prosthodontics. $4^{\text {th }}$ Ed. St. Louis /; MOSBY. P.341-2.

4. Sharafeddin F, Alavi AA, Talei Z. Flexural strength of glass and polyethylene fiber combined with three different composite. J Dent Shiraz Univ Med Scien. 2013; 14(1): 13 .

5. Mohan S, Gurtu A, Singhai A, Guha C. Fiber reinforced composite-a review and case report. J Dent Sci \& Oral Rehabil [Internet]. 2012 [cited 2017 Feb 10]. Available from: http://www.jdsor.com/2012-ISSUE-2/A12.pdf

6. Strassler HE. Clinical materials review fiber reinforce materials for dental resins. Inside Dentistry [Internet]. 2008 [cited 2017 Feb 10]. Available from: https://www. dentalaegis.com/id/2008/05/fiber-reinforcing-materialsfor-dental-resins

7. Belli S, Eskitascioglu. Biomechanical properties and clinical use of polyethylene fiber post-core material. Int Dentistry South Africa. 2006;8(3):21-8.
8. Agrawal M, Vadodara. Applications of ultrahigh molecular weight polyethylene fibers in dentistry: a review article. J Adv Med Den Scie Res. 2014;2(2):95-7.

9. Costa S, Silva YS, Curylofo F, Steier L, Neto MS, Gabriel AS.. Fracture resistance of mechanically compromised premolars restored with polyethylene fiber and adhesive materials. Int J Adhes. Adhes. 2014;50:211-5.

10. Goracci C, Ferrari M. Current presperctive on post systems: a literature review. ADA. 2011;56(1):77-83.

11. Li X, Shi Y, Li z, dkk. Three dimensional finite element analysis of maxilarry central incisor restored with different post core materials. Int Chin J Dent. 2008;8:21-7.

12. Lamichhane A, Xu C, Qiang FZ. Dental fiber post resin base material: A review. $J$ Adv Prosthodont. 2014;6:60-5.

13. Futardo A, Oro AS, Gallafassi D, Correr LS, Carlini BJ. Influence of ferulle preparation with or wothout glass fiber post on fracture resistance of endodontically reated teeth. J Appl Oral Sci. 2010;18(4):360-4.

14. Krishna RA, Aajjan S, Ramaruju VA, Ginjupalli K, Upadhya N. Influence of fiber reinforcement on the properties of denture base resins. J Biomat Nanobiotech. 2013;4:92-4.

15. Newman PM, Yaman P, Dennison J, Rafter M, Billy E. Fracture resistance of endodontically treated teeth restored with composite post. J Prosthet Dent. 2003;89(4)361-6.

16. Rubina, Kumar M, Garg R, Saini, Kausal S. Prosthosontic management of endodontically treated teeth-a review. Int J Student's Res. Feb-May2013;1(4):7.

17. Bacchi A, Santos MBF, Pimentel MJ, Caetano CR, Sinhoretti MAC, Consani RL. Influence of post thickness and material on the fracture strength of teeth with reduce coronal structure. J Conserv Dent. 2013;16(2):139-143.

18. Babic JZ, Panduric J, Jerolimov V, Mioc M, Pizeta I, Jakovac M. Bite force in subject with complete dentition. Coll Antropol 2002;26(1):293-302. 